\title{
Prognosis and Treatment After Diagnosis of Recurrent Esophageal Carcinoma Following Esophagectomy with Curative Intent
}

\author{
K. Parry, MD ${ }^{1}$, E. Visser, MD ${ }^{1}$, P. S. N. van Rossum, MD ${ }^{1,2}$, N. Haj Mohammad, MD ${ }^{3}$, J. P. Ruurda, MD, PhD ${ }^{1}$, and \\ R. van Hillegersberg, $\mathrm{MD}, \mathbf{P h D}^{1}$
}

${ }^{1}$ Department of Surgery, University Medical Center Utrecht, Utrecht, The Netherlands; ${ }^{2}$ Department of Radiotherapy, University Medical Center Utrecht, Utrecht, The Netherlands; ${ }^{3}$ Department of Medical Oncology, University Medical Center Utrecht, Utrech, The Netherlands

\begin{abstract}
Background. Strategies for the treatment of recurrence after initial curative esophagectomy are increasingly being recognized. The aim of this study was to identify prognostic factors that affect survival in patients with recurrence and to evaluate treatment strategies.

Methods. A prospective database (2003-2013) was used to collect consecutive patients with esophageal carcinoma treated with initial curative esophagectomy. Locations, symptoms, and treatment of recurrence were registered. Post-recurrence survival was defined as the time between the first recurrence and death or last follow-up.

Results. Of the 335 selected patients, 171 (51\%) developed recurrence. Multivariable analysis identified distant recurrence as opposed to locoregional recurrence [hazard ratio (HR) $2.15,95 \%$ confidence interval (CI) 1.27-3.65; $p=0.005]$, more than three recurrent locations (HR 2.42, $95 \%$ CI $1.34-4.34 ; p=0.003$ ), and treatment (HR 0.29, $95 \%$ CI $0.20-0.44 ; p<0.001)$ as independent prognostic factors associated with post-recurrence survival. Primary tumor characteristics, including neoadjuvant therapy, histological type, pTN stage, and radicality, did not independently influence post-recurrence survival. Treatment was initiated in 62 patients $(37 \%)$ and included chemotherapy, radiotherapy,
\end{abstract}

K. Parry and E. Visser share first authorship.

(C) The Author(s) 2015. This article is published with open access at Springerlink.com

First Received: 27 May 2015;

Published Online: 3 September 2015

R. van Hillegersberg, $\mathrm{MD}, \mathrm{PhD}$

e-mail: r.vanHillegersberg@umcutrecht.nl and/or surgery. Median post-recurrence survival of all patients was 3.0 months (range $0-112$ ). In total, six patients (4\%) were still disease-free following treatment, indicating cure.

Conclusions. In patients treated for esophageal cancer at curative intent, distant recurrence and more than three recurrent locations were independent prognostic factors associated with worse post-recurrence survival, irrespective of primary tumor characteristics. Although survival after recurrence was poor, treatment can prolong survival and can even lead to cure in selected patients.

Esophageal carcinoma is the sixth leading cause of cancer-related mortality worldwide and the incidence is rapidly increasing. ${ }^{1,2}$ Multimodality treatment combining neoadjuvant chemo(radio)therapy and surgical resection has improved the prognosis for resectable nonmetastatic disease $;^{3}$ however, more than half of the patients develop recurrence within 3 years after treatment with curative intent. $^{4-7}$ The prognosis of recurrent esophageal cancer is poor, with a median survival of 3-10 months after developing a recurrence. ${ }^{4,8-10}$ Therefore, detecting prognostic factors affecting post-recurrence survival and determining effectiveness of treatment strategies for recurrence are of high importance. Treatment can be attempted in a fair number of patients with recurrent disease and may include chemotherapy, radiotherapy, surgery, or a combination. ${ }^{9,11,12}$ However, the optimal treatment strategy for esophageal cancer patients with recurrent disease is not yet established and patients respond differently to treatment, with a wide range in long-term survival. ${ }^{12}$

The main aim of this study was to investigate prognostic factors that affect survival in patients diagnosed with recurrent disease after prior esophagectomy with curative 
intent for esophageal carcinoma. In addition, a second aim was to evaluate the different treatment strategies applied.

\section{METHODS}

\section{Patients}

In this single-center cohort study, patients were selected from a prospectively assembled database at the University Medical Center Utrecht, Utrecht, The Netherlands. Between October 2003 and December 2013, a total of 379 consecutive patients underwent esophagectomy with curative intent for esophageal carcinoma. Patients with an unresectable tumor (cT4b) or metastatic disease (M1) detected intraoperatively were excluded $(n=22)$, as were patients deceased within 90 days after surgery or during hospitalization $(n=22)$. Of the remaining 335 patients, 171 were diagnosed with recurrent disease and were included in the current study. All patients were discussed at a multidisciplinary tumor board meeting preoperatively, postoperatively, and after developing recurrent disease. Institutional Review Board approval was obtained, and the informed consent requirement was waived for this study.

\section{Treatment}

Eligible patients with locally advanced disease (cT $\geq 2$ or $\mathrm{cN}+$ ) and without clinical evidence of metastatic disease (cM0) received either perioperative chemotherapy or neoadjuvant chemoradiation according to the Dutch guidelines. Eligible patients were $>18$ years of age, had a WHO performance status $\leq 2$, and did not lose $>10 \%$ of their body weight. Before 1 June 2012, the standard treatment for patients with esophageal carcinoma consisted of perioperative chemotherapy (epirubicin, cisplatinum, and 5-fluorouracil), ${ }^{14}$ and after that patients underwent neoadjuvant chemoradiation (carboplatin AUC2 and paclitaxel $50 \mathrm{mg} / \mathrm{m}^{2}$ weekly during 5 weeks concomitant with 41.4 Gy $(23 \times 1.8 \mathrm{~Gy}) .^{3}$ Before 2008 , neoadjuvant therapy was not part of the standard protocol and most patients were operated on without this treatment. Patients not eligible for neoadjuvant treatment were treated with esophageal resection alone. After esophagectomy with en bloc lymphadenectomy, all patients underwent gastric tube reconstruction with a leftsided cervical anastomosis.

\section{Histopathological Analysis}

The resected specimens were reviewed by experienced pathologists in accordance with the TNM-7 staging system of the AJCC. ${ }^{13}$ Resection margins were evaluated using the definitions of the College of American Pathologists. ${ }^{15,16}$

\section{Follow-Up and Definition of Recurrence}

After esophagectomy, patients were followed at the outpatient clinic with an interval of 3 months in the first year, 6 months in the second year, and 12 months thereafter until discharge after 5 years of follow-up, which consisted of medical history and physical examination. In case of clinical suspicion of tumor recurrence, diagnostic imaging was performed. Recurrence was confirmed by histopathological biopsy or clinical follow-up, and only the initial number and sites of recurrences were evaluated. The pattern of recurrence was classified as locoregional, distant, or a combination of both. Recurrences at the anastomotic site or within the area of previous resection and nodal clearance in the mediastinum or upper abdomen were classified as locoregional recurrence, while distant recurrence was defined as recurrence in distant organs, pleura or peritoneal cavity, or distant lymph nodes. Disease-free survival was defined as the time between the day of surgery and day of recurrent disease, and post-recurrence survival was defined as the time between the first recurrence and death or last follow-up.

\section{Treatment of Recurrence}

Treatment for recurrent disease was discussed at a multidisciplinary tumor board meeting and was recommended if the patient was eligible. General considerations regarding eligibility included patient condition, location of recurrences, prior toxicity from chemotherapy or radiotherapy, and patient's wish. Treatment consisted of chemotherapy, radiotherapy, and/or surgery focused on tumor reduction. Radiotherapy focused on tumor reduction was defined as radiotherapy with a radiation dose $>30 \mathrm{~Gy}$, excluding palliative radiotherapy for bone metastases. In all other cases, patients were treated with best supportive care.

\section{Statistical Analysis}

To assess prognostic factors for post-recurrence survival, univariable and multivariable analyses by means of Cox proportional hazard models were used, providing hazard ratios (HRs) with $95 \%$ confidence intervals (CIs). All variables with a $p$ value $<0.20$ in univariable analysis were entered in a multivariable analysis. Kaplan-Meier survival curves were constructed for the prognostic factors that remained significantly associated with post-recurrence survival in multivariable analysis. A $p$ value $<0.05$ was considered statistically significant. All statistical analyses 
were performed using IBM SPSS version 21 for Windows (IBM Corporation, Armonk, NY, USA).

\section{RESULTS}

\section{Patient Characteristics}

Median follow-up of the 335 consecutive patients treated with esophagectomy during the study period was 22.0 months (range 2-135). Of all patients, 171 (51\%) developed recurrent disease, and these patients were included in the current study. The clinical and histopathological characteristics of these 171 patients are shown in Table 1. Mean age was 63 years (standard deviation 8.8) and most patients were male $(n=131$, $77 \%$ ). Perioperative chemotherapy was administered in 63 patients $(37 \%)$ and neoadjuvant chemoradiation in 35 patients $(21 \%)$. The surgical procedure consisted of a transthoracic approach in 132 patients $(77 \%)$ and a transhiatal approach in the remaining 39 patients (23\%). Tumor histology was adenocarcinoma in 136 patients $(80 \%)$, and histopathology revealed $\geq$ pT3 $(n=129$, $75 \%)$ and $\mathrm{pN}+$ disease $(n=123,72 \%)$ in the majority of patients. Of all patients who developed a recurrence, 139 (81\%) underwent a microscopically radical (R0) resection.

\section{Pattern of Recurrence}

Median time to recurrence was 9.0 months (range 1-86) and 164 patients $(96 \%)$ developed recurrence within 3 years after surgery. The most common presenting symptoms were pain $(n=38,22 \%)$, malaise $(n=23$, $14 \%)$, dysphagia $(n=21,12 \%)$, and anorexia $(n=21$, $12 \%)$. The diagnosis of recurrent disease was based on computed tomography (CT) findings in 118 patients (69\%), whereas in other patients the diagnosis was made with either endoscopic ultrasound (EUS), upper endoscopy, positron emission tomography (PET), or magnetic resonance imaging (MRI). The type of recurrence and the number of locations are presented in Table 2. Distant recurrence was the most common type of recurrent disease ( $n=76,44 \%$ ), and the liver was the most commonly affected site $(n=50,15 \%)$.

\section{Factors Affecting Post-recurrence Survival}

Median post-recurrence survival was 3.0 months (range 0-112), and the overall 1- and 2-year post-recurrence survival rates were 17 and $7 \%$, respectively. Nodal status, type of recurrence, number of locations, time to recurrence, and treatment of recurrence were significantly associated with post-recurrence survival in univariable analysis
TABLE 1 Clinical and histopathological characteristics of 171 patients with recurrent disease after esophagectomy with curative intent

\begin{tabular}{|c|c|}
\hline & $\begin{array}{l}\text { Recurrence } \\
(\text { Total }=171) \\
n(\%)\end{array}$ \\
\hline \multicolumn{2}{|l|}{ Gender } \\
\hline Male & $131(77)$ \\
\hline Female & $40(23)$ \\
\hline Age, years $($ mean $\pm S D)$ & $63 \pm 8.8$ \\
\hline \multicolumn{2}{|l|}{ ASA score } \\
\hline 1 & $49(29)$ \\
\hline 2 & $95(56)$ \\
\hline$\geq 3$ & $27(16)$ \\
\hline \multicolumn{2}{|l|}{ Neoadjuvant therapy } \\
\hline No neoadjuvant therapy & $72(42)$ \\
\hline Chemotherapy & $63(37)$ \\
\hline Radiotherapy & $1(1)$ \\
\hline Chemoradiation & $35(21)$ \\
\hline \multicolumn{2}{|l|}{ Surgical approach } \\
\hline Transthoracic & $132(77)$ \\
\hline Transhiatal & $39(23)$ \\
\hline \multicolumn{2}{|l|}{ Adjuvant therapy } \\
\hline No adjuvant therapy & $137(80)$ \\
\hline Chemotherapy & $34(20)$ \\
\hline \multicolumn{2}{|l|}{ Histological type } \\
\hline Adenocarcinoma & $136(80)$ \\
\hline Squamous cell carcinoma & $34(20)$ \\
\hline Other & $1(<1)$ \\
\hline \multicolumn{2}{|l|}{ pT stage } \\
\hline T0 & $9(5)$ \\
\hline $\mathrm{T} 1$ & $16(9)$ \\
\hline $\mathrm{T} 2$ & $17(10)$ \\
\hline $\mathrm{T} 3$ & $121(71)$ \\
\hline $\mathrm{T} 4 \mathrm{a}$ & $8(5)$ \\
\hline \multicolumn{2}{|l|}{$\mathrm{pN}$ stage } \\
\hline NO & $48(28)$ \\
\hline N1 & $49(29)$ \\
\hline N2 & $47(28)$ \\
\hline N3 & $27(16)$ \\
\hline $\begin{array}{l}\text { Number of harvested lymph nodes (median } \\
\text { [range]) }\end{array}$ & $20[2-80]$ \\
\hline \multicolumn{2}{|l|}{ Radicality } \\
\hline R0 & $139(81)$ \\
\hline $\mathrm{R} 1$ & 32 (19) \\
\hline
\end{tabular}

ASA American Society of Anesthesiologists, $S D$ standard deviation

(Table 3; Fig. 1). In multivariable analysis, distant recurrence (HR 2.15, $95 \%$ CI 1.27-3.65; $p=0.005$ ), more than three recurrent tumor locations (HR 2.42, $95 \%$ CI 
TABLE 2 Location and treatment recurrence of 171 patients with recurrent disease after esophagectomy with curative intent

Recurrence $($ Total $=171)$ $n(\%)$

\begin{tabular}{ll}
\hline Type of recurrence & $27(16)$ \\
Locoregional & $76(44)$ \\
Distant & $68(40)$ \\
Combined & \\
Location distant recurrence & $50(15)$ \\
Liver & $41(13)$ \\
Lung & $40(12)$ \\
Abdominal lymph nodes & $40(12)$ \\
Retroperitoneal & $30(9)$ \\
Bone & $123(38)$ \\
Other & \\
Number of locations with recurrence & $49(29)$ \\
1 & $62(36)$ \\
$2-3$ & $60(35)$ \\
$>3$ & \\
Type of management & $62(37)$ \\
Treatment focused on tumor reduction & $24(14)$ \\
Chemotherapy & $11(6)$ \\
Radiotherapy & $13(8)$ \\
Chemoradiation & $5(3)$ \\
Surgery & $4(2)$ \\
Surgery + chemotherapy & $4(2)$ \\
Surgery + radiotherapy & $1(1)$ \\
Other & $109(63)$ \\
Best supportive care & $63(37)$ \\
Condition & $29(17)$ \\
Patient wish & $4(2)$ \\
Toxicity & $4(2)$ \\
Location & $6(4)$ \\
Other & $3(2)$ \\
\hline
\end{tabular}

$1.34-4.34 ; p=0.003$ ), and treatment (HR 0.29, $95 \%$ CI $0.20-0.44 ; p<0.001)$ were identified as independent prognostic factors associated with post-recurrence survival (Table 3). The median post-recurrence survival of patients with distant and locoregional recurrence was 2.0 months and 12.0 months respectively. This was respectively 2.0 and 6.0 months for patients with more than three recurrent tumor locations and a solitary recurrence. Patients who received treatment focused on tumor reduction had a median post-recurrence survival of 9.0 months compared with 2.0 months in patients treated with best supportive care. Primary tumor characteristics, including neoadjuvant therapy, histological type, pTN stage, and radicality of resection, did not independently influence post-recurrence survival in multivariable analysis.

\section{Treatment of Recurrence}

Patients receiving best supportive care $(n=109,63 \%)$ were mainly either not eligible for treatment due to a poor performance status $(n=63,37 \%)$ or refused treatment $(n=29,17 \%)$. Some patients were not eligible due to prior toxicity of the neoadjuvant treatment regimen $(n=4$, $4 \%$ ) or tumor location $(n=4,4 \%)$. Treatment focused on tumor reduction was applied in 62 patients $(37 \%)$ (Table 2). Patients with locoregional recurrence $(n=19$, $70 \%)$ and solitary recurrence $(n=24,49 \%)$ more often received treatment focused on reduction compared with those with distant recurrence $(26,34 \%)$ and more than three recurrent tumor locations $(n=14,23 \%)$. Different chemotherapy regimens were administered in 41 patients, with most patients receiving a combination of epirubicin, cisplatin, and capecitabine $(n=20,48 \%)$. After treatment with chemotherapy only, two patients $(5 \%)$ showed a clinically complete tumor regression-one patient had a solitary metastasis in the liver, and the other had a solitary locoregional recurrence in the gastric conduit and truncal node. Both patients were alive at last follow-up (35 and 112 months after diagnosis of recurrence).

In 13 of 171 patients $(8 \%)$, surgical resection of the recurrence was performed (Table 4), with most of these patients having a solitary recurrence $(n=9,69 \%)$ at a distant location $(n=11,85 \%)$. Surgical resections are outlined in Table 4; five patients (38\%) underwent metastasectomy of a brain lesion. Median post-recurrence survival in patients who underwent resection was 11 months (95\% CI 4.5-17.5), and in 11 of 13 patients (85\%) the resection was performed with curative intent. Of these patients, 4 of 11 (36\%) were still alive at last follow-up, with a follow-up of 5, 46, 53, and 87 months after the diagnosis of their recurrence, whereas the remaining seven patients $(64 \%)$ deceased due to disease progression.

\section{DISCUSSION}

In this single-center cohort study, 171 patients with recurrent disease after treatment with curative intent for esophageal carcinoma were analyzed and factors affecting post-recurrence survival were evaluated. Distant recurrence and more than three recurrent locations were identified as independent prognostic factors associated with a worse post-recurrence survival, irrespective of primary tumor characteristics. Furthermore, treatment focused on tumor reduction, as opposed to best supportive care, prolonged 
TABLE 3 Univariable and multivariable analysis of potential prognostic factors for survival after diagnosis of recurrent esophageal carcinoma

\begin{tabular}{|c|c|c|c|c|c|c|}
\hline & HR & $95 \% \mathrm{CI}$ & $p$-Value ${ }^{\mathrm{a}}$ & HR & $95 \% \mathrm{CI}$ & $p$-Value ${ }^{\mathrm{b}}$ \\
\hline Age (years) & 1.02 & $1.00-1.04$ & 0.055 & 1.00 & $0.99-1.02$ & 0.670 \\
\hline \multicolumn{7}{|l|}{ Neoadjuvant therapy } \\
\hline None & Reference & - & - & Reference & - & - \\
\hline Chemotherapy & 1.39 & $0.98-1.99$ & 0.067 & 1.02 & $0.70-1.49$ & 0.936 \\
\hline Radiotherapy & 3.45 & $0.47-25.23$ & 0.222 & 7.85 & $0.99-62.54$ & 0.052 \\
\hline Chemoradiation & 1.26 & $0.82-1.94$ & 0.297 & 0.84 & $0.50-1.41$ & 0.512 \\
\hline \multicolumn{7}{|l|}{ Histological type } \\
\hline Adenocarcinoma & Reference & - & - & & & \\
\hline Squamous cell carcinoma & 1.24 & $0.84-1.84$ & 0.272 & & & \\
\hline Other & 1.10 & $0.15-7.93$ & 0.922 & & & \\
\hline \multicolumn{7}{|l|}{ pT stage } \\
\hline T0 & Reference & - & - & Reference & - & - \\
\hline $\mathrm{T} 1-2$ & 0.47 & $0.21-1.06$ & 0.067 & 0.60 & $0.25-1.41$ & 0.243 \\
\hline T3-4 & 0.70 & $0.34-1.45$ & 0.341 & 0.78 & $0.34-1.76$ & 0.545 \\
\hline \multicolumn{7}{|l|}{ pN stage } \\
\hline No & Reference & - & - & Reference & - & - \\
\hline N1 & 1.80 & $1.18-2.75$ & 0.007 & 1.50 & $0.95-2.37$ & 0.080 \\
\hline $\mathrm{N} 2-3$ & 1.35 & $0.91-1.99$ & 0.131 & 1.10 & $0.70-1.73$ & 0.689 \\
\hline \multicolumn{7}{|l|}{ Radicality } \\
\hline R0 & Reference & - & - & & & \\
\hline $\mathrm{R} 1$ & 1.20 & $0.81-1.77$ & 0.363 & & & \\
\hline \multicolumn{7}{|l|}{ Type of recurrence } \\
\hline Locoregional & Reference & - & - & Reference & - & - \\
\hline Distant & 2.10 & $1.30-3.41$ & 0.003 & 2.15 & $1.27-3.65$ & 0.005 \\
\hline Combined & 2.54 & $1.55-4.16$ & $<\mathbf{0 . 0 0 1}$ & 1.58 & $0.89-2.81$ & 0.120 \\
\hline \multicolumn{7}{|l|}{ Number of locations } \\
\hline 1 & Reference & - & - & Reference & - & - \\
\hline $2-3$ & 1.21 & $0.81-1.79$ & 0.357 & 1.30 & $0.83-2.00$ & 0.250 \\
\hline$>3$ & 2.20 & $1.46-3.32$ & $<\mathbf{0 . 0 0 1}$ & 2.42 & $1.34-4.34$ & 0.003 \\
\hline Time to recurrence (months) & 0.98 & $0.96-1.00$ & 0.013 & 0.99 & $0.98-1.01$ & 0.263 \\
\hline \multicolumn{7}{|l|}{ Treatment of recurrence } \\
\hline Best supportive care & Reference & - & - & Reference & - & - \\
\hline Treatment focused on tumor reduction & 0.27 & $0.19-0.38$ & $<\mathbf{0 . 0 0 1}$ & 0.29 & $0.20-0.44$ & $<\mathbf{0 . 0 0 1}$ \\
\hline
\end{tabular}

Analysis was performed using a Cox regression model

Bold values indicate statistically significant (e.g. $p<0.05$ ). All variables with a $p$ value $<0.2$ from univariable analysis were used for multivariable analysis

$H R$ hazard ratio, $C I$ confidence interval

${ }^{\text {a }}$ Univariable analysis

b Multivariable analysis

survival in eligible patients and a selected group of patients were treated curatively.

This study confirms the poor prognosis of recurrent esophageal cancer reported in other series ${ }^{4,8,9,10}$ with a median post-recurrence survival of 3.0 months and a 2 -year survival rate of only $7 \%$. Hence, understanding of the prognostic factors influencing survival is important in identifying patients who could have an improved post- recurrence survival by selecting them for the appropriate treatment. In accordance with the literature, distant recurrence was associated with a worse survival in this study, reflecting aggressive tumor biology. ${ }^{6,12,17}$ Furthermore, this study showed that patients with more than three recurrent tumor locations had a worse post-recurrence survival compared with those with less involved locations, which could also be explained by the more aggressive behavior of 


\section{Type of recurrence}

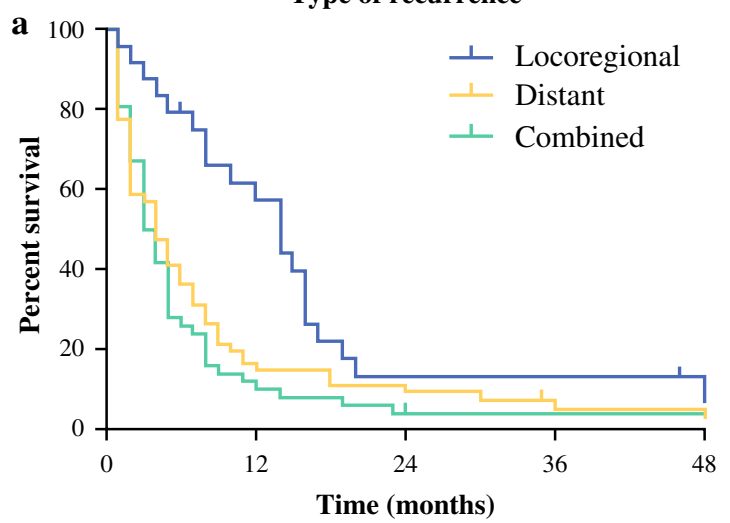

\begin{tabular}{|lccccc|}
\hline \multicolumn{2}{l}{ Number at risk: } & & & & \\
Locoregional 27 & 13 & 3 & 3 & 2 \\
Distant & 76 & 8 & 5 & 2 & 2 \\
Combined & 68 & 5 & 1 & 1 & 1 \\
\hline
\end{tabular}

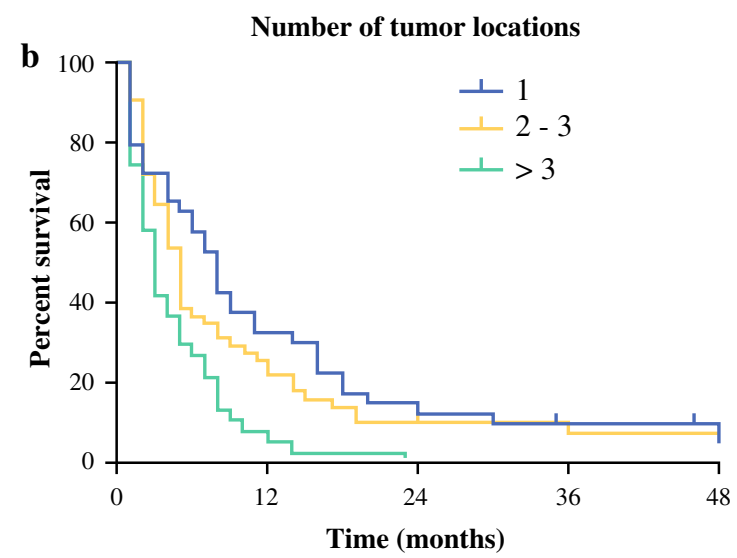

\begin{tabular}{|llllll|}
\hline \multicolumn{2}{l}{ Number at risk: } & & & & \\
1 & 49 & 13 & 5 & 3 & 2 \\
$2-3$ & 62 & 13 & 4 & 3 & 3 \\
$>3$ & 60 & 2 & 0 & 0 & 0 \\
\hline
\end{tabular}

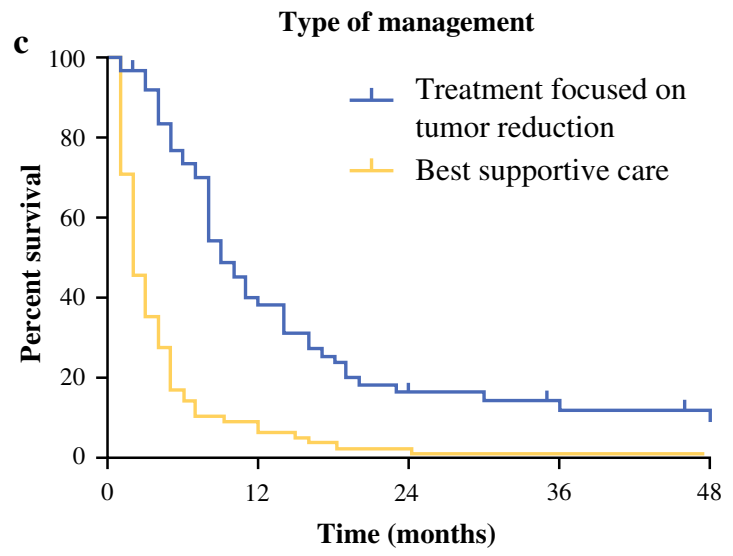

\begin{tabular}{|lccccc|}
\hline Number at risk: & & & & \\
Treatment & 62 & 22 & 8 & 5 & 4 \\
BSC & 109 & 5 & 1 & 1 & 1 \\
\hline
\end{tabular}

4 FIG. 1 a Type of recurrence, b number of tumor locations, and c type of management were identified as independent prognostic variables for post-recurrence survival in 171 patients with recurrent disease after curative esophagectomy. Survival curves were plotted using the Kaplan-Meier method

multiple recurrences. The survival of patients with more than three recurrent locations was extremely poor, with a median survival of 2.0 months after the diagnosis of recurrence compared with 6.0 months in patients with a solitary recurrence. The majority of patients had a poor clinical condition at the time of diagnosis of recurrence and were therefore considered ineligible for treatment focused on tumor reduction. The patients who underwent treatment had a significantly prolonged survival, which is likely explained by a combination of appropriate patient selection and treatment effectiveness.

As has been reported in previous studies, ${ }^{4,9,18}$ all different treatment strategies resulted in a prolonged survival in the current study. This finding suggests that all patients with recurrent disease should be stimulated to undergo treatment if the condition of patients allows it. Median post-recurrence survival in the treated group was 9.0 months compared with 2.0 months for those who were treated with best supportive care. It needs to be acknowledged that the majority of patients who received best supportive care were not eligible for therapy, causing bias through selection-by-indication in this comparison. Nonetheless, most patients who were not eligible had advanced disease (i.e. distant recurrence or more than three recurrent locations), which reflects high dependency of the patient's condition on the site and number of recurrent tumors.

Patients were treated with various therapies, of which chemotherapy was the most commonly applied. The benefit of a surgical resection of recurrent esophageal carcinoma is not yet completely elucidated. A few reports showed improved survival after surgical resection; ${ }^{11,19,20}$ however, in most studies the resection was combined with either chemotherapy or radiotherapy and was performed in only a small number of patients. Also in this study, a small group of patients $(n=13)$ underwent resection of their recurrence, the majority $(n=9)$ of whom had an oligometastasis. Patients with oligometastases represent a special tumor behavior that is likely to gain from local control. In other types of cancer, the current literature also shows a survival benefit with long disease-free survival from local control with surgery for patients with oligometastases. ${ }^{21,22}$ Importantly, four patients had complete tumor remission after the resection and were still alive at last follow-up. Other studies also reported longterm survival after treatment of recurrent disease for esophageal carcinoma. ${ }^{11,23-25}$ These findings suggest that a 
TABLE 4 Characteristics, treatment, and survival of 13 patients treated with surgical resection for recurrent esophageal carcinoma

\begin{tabular}{|c|c|c|c|c|c|c|c|c|c|c|c|c|}
\hline \multirow[t]{2}{*}{ Case } & \multirow[t]{2}{*}{$\begin{array}{l}\text { Age, } \\
\text { years }\end{array}$} & \multirow[t]{2}{*}{ Sex } & \multirow[t]{2}{*}{$\begin{array}{l}\text { pTNM } \\
\text { stage }\end{array}$} & \multirow{2}{*}{$\begin{array}{l}\text { Time to } \\
\text { recurrence } \\
\text { (months) }\end{array}$} & \multirow[t]{2}{*}{$\begin{array}{l}\text { Type of } \\
\text { recurrence }\end{array}$} & \multirow[t]{2}{*}{$\begin{array}{l}\text { Location } \\
\text { recurrence }\end{array}$} & \multirow[t]{2}{*}{$\begin{array}{l}\text { Surgical } \\
\text { intervention }\end{array}$} & \multicolumn{2}{|c|}{$\begin{array}{l}\text { Other } \\
\text { treatments }\end{array}$} & \multirow[t]{2}{*}{$\begin{array}{l}\text { Curative } \\
\text { intent }\end{array}$} & \multirow[t]{2}{*}{ Status } & \multirow{2}{*}{$\begin{array}{l}\text { Survival } \\
\text { after } \\
\text { recurrence } \\
\text { (months) }\end{array}$} \\
\hline & & & & & & & & $\mathrm{CT}$ & RT & & & \\
\hline 1 & 56 & Male & T3N2M0 & 11 & Distant & Abdominal LN & LN resection & No & No & Yes & Dead & 53 \\
\hline 2 & 44 & Male & T3N2M0 & 3 & Distant & $\begin{array}{l}\text { Abdominal wall } \\
\text { Inguinal cutane }\end{array}$ & $\begin{array}{l}\text { Tumor resection } \\
\text { Tumor resection }\end{array}$ & Yes & No & Yes & Dead & 9 \\
\hline 3 & 74 & Female & $\mathrm{T} 4 \mathrm{aN} 2 \mathrm{M} 0$ & 2 & Distant & $\begin{array}{l}\text { Upper leg } \\
\quad \text { subcutane } \\
\text { Inguinal LN } \\
\text { Abdominal wall } \\
\text { Abdominal LN }\end{array}$ & $\begin{array}{l}\text { Tumor resection } \\
\text { LN resection }\end{array}$ & No & Yes & No & Dead & 4 \\
\hline 4 & 67 & Male & T3N2M0 & 8 & Distant & $\begin{array}{l}\text { Brain, lung, } \\
\text { liver }\end{array}$ & $\begin{array}{l}\text { Metastasectomy } \\
\text { brain lesion }\end{array}$ & No & Yes & No & Dead & 5 \\
\hline 5 & 53 & Male & T0NOMO & 21 & Distant & Brain & $\begin{array}{l}\text { Metastasectomy } \\
\text { brain lesion }\end{array}$ & No & Yes & Yes & Dead & 7 \\
\hline 6 & 77 & Female & T3N0M0 & 14 & Distant & Brain & $\begin{array}{l}\text { Metastasectomy } \\
\text { brain lesion }\end{array}$ & No & No & Yes & Dead & 1 \\
\hline 7 & 75 & Male & T1bN0M0 & 31 & Distant & Lung & $\begin{array}{l}\text { Partial pulmonary } \\
\text { resection }\end{array}$ & No & No & Yes & Dead & 18 \\
\hline 8 & 62 & Female & T3N0M0 & 12 & Distant & Brain & $\begin{array}{l}\text { Metastasectomy } \\
\text { brain lesion }\end{array}$ & No & No & Yes & Dead & 4 \\
\hline 9 & 50 & Male & T3N0M0 & 32 & Distant & $\begin{array}{l}\text { Vesiculae } \\
\text { seminales }\end{array}$ & $\begin{array}{l}\text { Excision vesiculae } \\
\text { seminales }\end{array}$ & No & No & Yes & Dead & 11 \\
\hline \multirow[t]{2}{*}{10} & 65 & Male & T3N3M0 & 8 & Combined & $\begin{array}{l}\text { Quadriceps } \\
\text { muscles }\end{array}$ & $\begin{array}{l}\text { Paraesophageal } \\
\text { LN }\end{array}$ & & & & & \\
\hline & & & & & & $\begin{array}{l}\text { Metastasectomy } \\
\text { quadriceps } \\
\text { muscles }\end{array}$ & Yes & No & Yes & Alive & 87 & \\
\hline 11 & 56 & Male & T2N0M0 & 13 & Locoregional & Gastric conduit & $\begin{array}{l}\text { Resection gastric } \\
\text { conduit with } \\
\text { jejunal } \\
\text { reconstruction }\end{array}$ & No & No & Yes & Alive & 46 \\
\hline 12 & 65 & Male & T1aN0M0 & 10 & Distant & Liver & Hemihepatectomy & Yes & No & Yes & Alive & 53 \\
\hline 13 & 62 & Male & T3N0M0 & 20 & Distant & Brain & $\begin{array}{l}\text { Metastasectomy } \\
\text { brain lesion }\end{array}$ & No & Yes & Yes & Alive & 5 \\
\hline
\end{tabular}

$C T$ chemotherapy, $R T$ radiotherapy, $L N$ lymph node

favorable outcome can be expected after surgical resection in a selected patient group, especially for those with solitary or localized recurrence of esophageal cancer.

Although treatment of recurrence resulted in prolonged survival, the majority of patients $(63 \%)$ received best supportive care. This is in contrast with some other studies where the proportion of patients receiving best supportive care ranged from 12 to $44 \% ., 11,17,26,{ }^{27}$ An explanation for the high percentage of best supportive care in this cohort could lie in the follow-up strategy; the current follow-up strategy is based on the existing literature showing that routine diagnostic imaging is of no benefit with regard to survival and costs. ${ }^{28}$ Furthermore, the consensus-based guidelines from the National Comprehensive Cancer Network also suggest that diagnostic imaging should only be performed when clinically indicated. ${ }^{29}$ Hence, this followup strategy is widely performed in The Netherlands; however, it could have resulted in more advanced recurrent tumor stages at the moment of diagnosis. Since the patient's condition is largely determined by the number and site of recurrences, patients with multiple metastases are often not eligible for therapy; therefore, the follow-up strategy may need revision according to the findings of the current study. In light of new insights into the concept of oligometastases and the new combined treatment options, we suggest routinely performing a follow-up of patients with PET CT in the first 6-12 months following primary treatment. ${ }^{30}$ Another explanation for the high 'best supportive care' rate could be the large proportion of patients $(27 \%)$ who refused any form of treatment. In most other 
studies, only a fraction of patients did not receive treatment based on patient's choice. ${ }^{17,26,27}$ According to the results of the current study, eligible patients might be encouraged to have treatment focused on tumor reduction to improve their survival. Unfortunately, no information on quality of life, which is of paramount importance in patients being treated with palliative intent, was obtained from patients who were treated for recurrence.

\section{CONCLUSIONS}

Survival after developing a recurrence after esophagectomy with curative intent is poor. Distant recurrence and more than three recurrent locations were identified as independent factors associated with a worse survival, irrespective of primary tumor characteristics. Treatment focused on tumor reduction using various strategies contributed to a prolonged survival in all patients. Hence, stronger focus is needed to improve patient selection for treatment in recurrent esophageal carcinoma. Additionally, in a small group of patients $(4 \%)$, curative treatment of recurrent esophageal carcinoma appears possible.

OPEN ACCESS This article is distributed under the terms of the Creative Commons Attribution 4.0 International License (http:// creativecommons.org/licenses/by/4.0/), which permits unrestricted use, distribution, and reproduction in any medium, provided you give appropriate credit to the original author(s) and the source, provide a link to the Creative Commons license, and indicate if changes were made.

\section{REFERENCES}

1. Torre LA, Bray F, Siegel RL, Ferlay J, Lortet-Tieulent J, Jemal A. Global cancer statistics, 2012. CA Cancer J Clin. 2015;65:87108.

2. Pennathur A, Gibson MK, Jobe BA, Luketich JD. Oesophageal carcinoma. Lancet. 2013;381:400-412.

3. van Hagen P, Hulshof MC, van Lanschot JJ, et al. Preoperative chemoradiotherapy for esophageal or junctional cancer. $N$ Engl $J$ Med. 2012;366:2074-2084.

4. Dresner SM, Griffin SM. Pattern of recurrence following radical oesophagectomy with two-field lymphadenectomy. $\mathrm{Br} J$ Surg. 2000;87:1426-1433.

5. Nakagawa S, Kanda T, Kosugi S, Ohashi M, Suzuki T, Hatakeyama K. Recurrence pattern of squamous cell carcinoma of the thoracic esophagus after extended radical esophagectomy with three-field lymphadenectomy. J Am Coll Surg. 2004;198:205211.

6. Mariette C, Balon JM, Piessen G, Fabre S, Van Seuningen I, Triboulet JP. Pattern of recurrence following complete resection of esophageal carcinoma and factors predictive of recurrent disease. Cancer. 2003;97:1616-1623.

7. Hulscher JB, van Sandick JW, Tijssen JG, Obertop H, van Lanschot JJ. The recurrence pattern of esophageal carcinoma after transhiatal resection. J Am Coll Surg. 2000;191:143-148.

8. Kunisaki C, Makino H, Takagawa R, et al. Surgical outcomes in esophageal cancer patients with tumor recurrence after curative esophagectomy. J Gastrointest Surg. 2008;12:802-810.
9. Blom RL, Lagarde SM, van Oudenaarde K, et al. Survival after recurrent esophageal carcinoma has not improved over the past 18 years. Ann Surg Oncol. 2013;20:2693-2698.

10. Abate E, DeMeester SR, Zehetner J, et al. Recurrence after esophagectomy for adenocarcinoma: defining optimal follow-up intervals and testing. J Am Coll Surg. 2010;210:428-435.

11. Hiyoshi Y, Morita M, Kawano H, et al. Clinical significance of surgical resection for the recurrence of esophageal cancer after radical esophagectomy. Ann Surg Oncol. 2015;22:240-246.

12. Su XD, Zhang DK, Zhang X, Lin P, Long H, Rong TH. Prognostic factors in patients with recurrence after complete resection of esophageal squamous cell carcinoma. J Thorac Dis. 2014;6: 949-957.

13. Edge SB, Compton CC. The American Joint Committee on Cancer: the 7th edition of the AJCC cancer staging manual and the future of TNM. Ann Surg Oncol. 2010;17:1471-1474.

14. Cunningham D, Allum WH, Stenning SP, et al. Perioperative chemotherapy versus surgery alone for resectable gastroesophageal cancer. N Engl J Med. 2006;355:11-20.

15. Deeter M, Dorer R, Kuppusamy MK, Koehler RP, Low DE. Assessment of criteria and clinical significance of circumferential resection margins in esophageal cancer. Arch Surg. 2009;144:618-624.

16. Verhage RJ, Zandvoort HJ, ten Kate FJ, van Hillegersberg R. How to define a positive circumferential resection margin in T3 adenocarcinoma of the esophagus. Am J Surg Pathol. 2011;35:919-926.

17. Kato H, Fukuchi M, Miyazaki T, et al. Classification of recurrent esophageal cancer after radical esophagectomy with two- or three-field lymphadenectomy. Anticancer Res. 2005;25:34613467.

18. Miyata H, Yamasaki M, Kurokawa Y, et al. Survival factors in patients with recurrence after curative resection of esophageal squamous cell carcinomas. Ann Surg Oncol. 2011;18:3353-3361.

19. Motoyama S, Saito R, Okuyama M, Maruyama K, Nanjo H, Ogawa J. Long-term survival after salvage resection of recurrent esophageal cancer with anterior mediastinal lymph node involvement: report of a case. Surg Today. 2006;36:827-830.

20. Yano M, Takachi K, Doki Y, et al. Prognosis of patients who develop cervical lymph node recurrence following curative resection for thoracic esophageal cancer. Dis Esophagus. 2006;19:73-77.

21. Salama JK, Chmura SJ. Surgery or ablative radiotherapy for breast cancer oligometastases. Am Soc Clin Oncol Educ Book. 2015;35:e8-e15.

22. Niibe Y, Hayakawa K. Oligometastases and oligo-recurrence: the new era of cancer therapy. Jpn J Clin Oncol. 2010;40:107-111.

23. Iitaka $D$, Shiozaki A, Fujiwara $H$, et al. Case involving long-term survival after esophageal cancer with liver and lung metastases treated by multidisciplinary therapy: report of a case. Surg Today. 2013;43:556-561.

24. Yamamoto T, Tachibana M, Kinugasa S, Yoshimura H, Nagasue $\mathrm{N}$. Esophagectomy and hepatic arterial chemotherapy following hepatic resection for esophageal cancer with liver metastasis. $J$ Gastroenterol. 2001;36:560-563.

25. Chen F, Sato K, Sakai H, et al. Pulmonary resection for metastasis from esophageal carcinoma. Interact Cardiovasc Thorac Surg. 2008;7:809-812.

26. Hsu PK, Wang BY, Huang CS, Wu YC, Hsu WH. Prognostic factors for post-recurrence survival in esophageal squamous cell carcinoma patients with recurrence after resection. J Gastrointest Surg. 2011;15:558-565.

27. Sugiyama M, Morita M, Yoshida R, et al. Patterns and time of recurrence after complete resection of esophageal cancer. Surg Today. 2012;42:752-758.

28. Sudo K, Taketa T, Correa AM, et al. Locoregional failure rate after preoperative chemoradiation of esophageal adenocarcinoma and the outcomes of salvage strategies. J Clin Oncol. 2013;31: 4306-4310. 
29. National Comprehensive Cancer Network (NCCN). NCCN Clinical practice guidelines in oncology. Available at: http:// www.nccn.org/professionals/physician_gls/f_guidelines.asp. Accessed 1 April 2014.

30. Goense L, van Rossum PS, Reitsma JB, et al. Diagnostic performance of 18F-FDG and PET/CT for the detection of recurrent esophageal cancer after treatment with curative intent: a systematic review and meta-analysis. J Nucl Med. 2015;56(7): 995-1002. 